\title{
A STABILITY INDICATING RP-HPLC METHOD DEVELOPMENT FOR SIMULTANEOUS ESTIMATION OF ALOGLIPTIN, PIOGLITAZONE, AND METFORMIN IN PHARMACEUTICAL FORMULATIONS
}

\author{
ISRAA W. HABASH', RAMADAN IBRAHIM AL-SHDEFAT2, \\ MOHAMMAD MAJED HAILAT ${ }^{3}$ and WAEL ABU DAYYIH ${ }^{1 *}$
}

'Faculty of Pharmacy and Medical Sciences, University of Petra, Amman, Jordan

${ }^{2}$ Faculty of Pharmacy, Jadara University, Irbid, Jordan

${ }^{3}$ Faculty of Pharmacy, Al-Zaytoonah University of Jordan, Amman, Jordan

\begin{abstract}
Alogliptin, dipeptidyl peptidase-4 (DPP-4) inhibitor, Pioglitazone, thiazolidinediones (TZDs) and Metformin, biguanides are antidiabetic drugs that usually used in the management of type 2 diabetes that can be used solely or as combinations. In this article, a selective, simple, economical, precise, and stability-indicating RP-HPLC method has been developed and validated for assessing Alogliptin, Pioglitazone, and Metformin inside the bulk drug and tablet pharmaceutical dosage form. The mobile phase that used to separate the drug was consists of acetonitrile: buffer (potassium dihydrogen phosphate), $(30: 70 \mathrm{v} / \mathrm{v})$ on an ACE C18 - $(250 \mathrm{~mm}$ $\times 4.6 \mathrm{~mm}$ ), $5 \mu \mathrm{m}$ column at a flow rate of $1.0 \mathrm{~mL} / \mathrm{min}$ at $25^{\circ} \mathrm{C}$ and detection was at $230 \mathrm{~nm}$. The linearity of the detector was established in concentrations ranging from 20-250 ppm; the regression coefficient was 0.9998. The ICH guidelines were followed to evaluate stability, where the API is stressed by acid, base, neutral, oxidation, and sunlight. Several parameters were used for validation, including linearity, precision, accuracy, the limit of detection, and limit of quantification. The results were fulfilling expectations based on ICH guidelines. Robustness of the method was verified in terms of changes in $\mathrm{pH}$ of the mobile phase, detector wavelength, mobile phase composition, and temperature. Also, the method results in low relative standard deviation and high recovery value, that ensure the convenience applicability of the method for routine analysis of tablet containing Alogliptin, Pioglitazone, and Metformin.
\end{abstract}

Keywords: stability-indicating assay method, RP-HPLC, accuracy, precision, robustness, validation, Alogliptin, Pioglitazone, Metformin

Diabetes Mellitus (DM) is one of the significant metabolic issues inclining unfriendly wellbeing nowadays (1). One of the hallmarks of DM is the presence of hyperglycemia in individuals who suffer from DM (2). Hyperglycemia, in the long term, is a reason for damage for several organs, including the eyes, kidneys, nerves, and others (2). There are two subtypes of DM, DM type I (insulin-dependent DM) and type II (adult-onset DM) (3). At present, there are different treatments, both oral and injectable, available for the treatment of DM type II (4). The selection of suitable therapy for DM hyperglycemia is based on the pathophysiological stage of the progressive disease at the onset of the start of therapy (1).

Alogliptin (Fig. 1) is a selective, orally bioavailable inhibitor of enzymatic activity of dipeptidyl peptidase-4 (DPP-4). Alogliptin is a promising treatment for type II DM with a lower frequency of severe hypoglycemia (2).

Pioglitazone (Fig. 1) is a Thiazolidinediones (TZDs). Pioglitazone exerts its action through its insulin-sensitizing effect that is usually used to treat DM of type II (3). The hypoglycemic effect of pioglitazone is believed to be through increasing the transactivation activity of Peroxisome Proliferators Activated Receptors (PPARs) (3).

Metformin is a member of biguanides; biguanides consist of two guanidine attached to others (4). Metformin is used to lower glucose that is used orally. It is known since 1957 as a treatment for non-insulin-dependent diabetes mellitus (NIDDM). It is known about metformin that it has the capability of lowering blood glucose, but it does not lead to

* Corresponding author: e-mail: wabudayyih@uop.edu.jo 


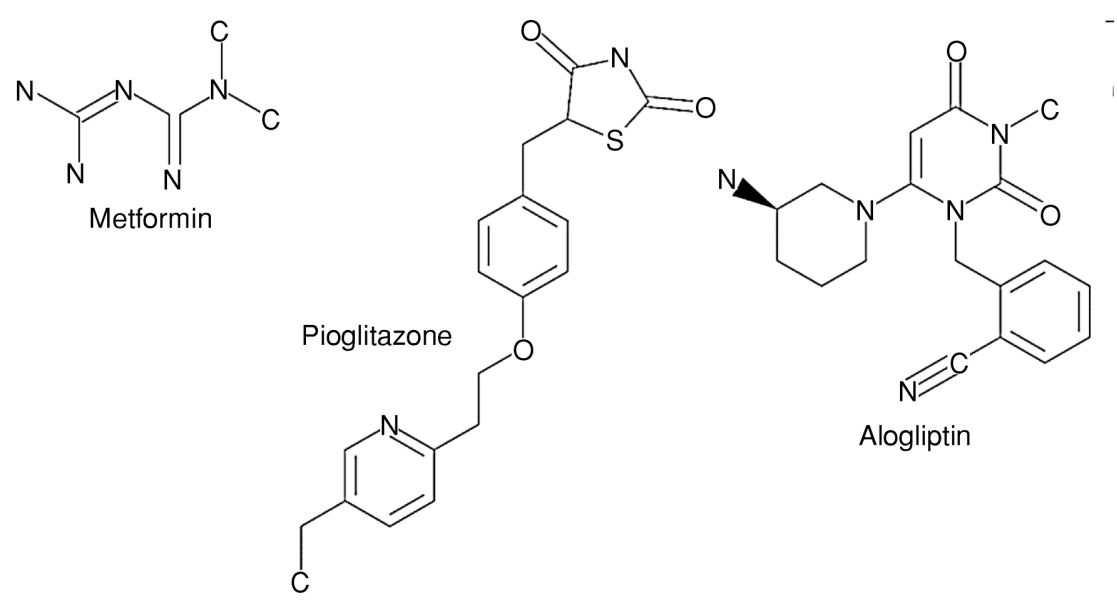

Figure 1. Chemical structure of Alogliptin, Pioglitazone, and Metformin.

elevation of insulin production but rather by increasing the use of glucose (5).

\section{Materials and methods}

The used chemicals and reagents were as follows: Orthophosphoric acid: AR grade, Acetonitrile: HPLC grade, Potassium hydrogen phosphate: AR grade, Water: Mille-Q grade, Methanol: HPLC grade. These chemicals were a generous gift from Hikma Pharmaceuticals - Sult. The following film-coated tablets (FCT) and drugs were kindly donated by Hikma Pharmaceuticals-Sult: Alogliptin/Metformin (12.5 mg/1000 mg) FCT batch number 857085, Alogliptin/Metformin (12.5 mg/500 mg) FCT batch number 857086, Alogliptin 12.5 mg FCT batch number 857008 , Alogliptin $25 \mathrm{mg}$ FCT batch number 857006, Alogliptin/Pioglitazone ( $25 \mathrm{mg} / 30 \mathrm{mg}$ ) FCT batch number 857082, Alogliptin benzoate batch number 366002, Pioglitazone $\mathrm{HCl}$ batch number 366122, and metformin $\mathrm{HCl}$ batch number 366014.

\section{Instrumentation}

The separation was achieved by using the column: ACE C18 -(250 mm x $4.6 \mathrm{~mm}), 5 \mu \mathrm{m}$. Lot number: 942. The analysis was performed on an HPLC (FINNIGAN SURVEYOR) (Thermo Electron Corporation, San Jose, CA, USA). Equipped with the detector (UV-VIS Plus Detector), the pump (solvent delivery systems pump) (LC Pump plus), and the autosampler (Autosampler Plus) (6).

\section{Chromatographic conditions}

The separation was under the following conditions: flow rate: $1.0 \mathrm{~mL}$ per min, column: ACE C18
(250 mm $\times 4.6 \mathrm{~mm}), 5 \mu \mathrm{m}$, detector wavelength: 230 $\mathrm{nm}$, column temperature: $25^{\circ} \mathrm{C}$, injection volume: $10 \mu \mathrm{L}$, run time: $5.0 \mathrm{~min}$, diluent: mobile phase: 30 : 70 (buffer: acetonitrile) The retention time under these conditions was equal to 2.14 which give a sharp peak with good symmetry for Metformin, Alogliptin: 3.22 and Pioglitazone: 3.57 (7).

\section{Mobile phase preparation}

In order to prepare the mobile phase, $300 \mathrm{~mL}$ of the buffer solution was mixed with $700 \mathrm{~mL}$ of acetonitrile. The $\mathrm{pH}$ of the resultant buffer was adjusted to be 3.4 using orthophosphoric acid. Then filtration of the resultant solution was carried out using a 0.45 ěm membrane filter followed by sonication to degas the solution (8).

Preparation of stock solutions and working solutions

In order to prepare stock solutions of Alogliptin, Pioglitazone and Metformin stock solution (4000 ppm), $100 \mathrm{mg}$ of each of the active ingredients were weighed and transferred to $25 \mathrm{~mL}$ volumetric flask and followed by adding diluent up to 25 $\mathrm{mL}$ to prepare the stock solution. Then $2,3.1,6.2$, 12.5 , and $25 \mathrm{~mL}$, respectively of each stock solution were used to prepare $50 \mathrm{~mL}$ of IS p-methoxyacetophenon.

\section{Preparation of internal standard}

Preparation of internal standard was done by weighing and transferring $100 \mathrm{mg}$ for p-methoxyacetophenon in a $25 \mathrm{~mL}$ volumetric flask and adding diluent up to volume, then transferring $0.8 \mathrm{~mL}$ in $5 \mathrm{~mL}$ to reach the final concentration of $4000 \mathrm{ppm}$. 


\section{Preparation of buffer}

Preparation of the buffer was carried out by dissolving about $6.8 \mathrm{gm}$ of potassium dihydrogen phosphate in $1000 \mathrm{~mL}$ of HPLC-grade water; the $\mathrm{pH}$ is adjusted to be 3.4 using orthophosphoric acid.

\section{Method validation}

In order to validate the method, investigation of the validity was carried out in two days, where six standard calibration levels were prepared. The validation parameters did not exceed the limits by the FDA Guidance (9).

\section{Precision of the system and preparation of the test samples}

A solution was prepared by dissolving Alogliptin, Pioglitazone, and Metformin. The solution is prepared by weighing and dissolving the three ingredients in $50 \mathrm{~mL}$ of the mobile phase solution as a solvent and repeatedly injected (10 injections).

\section{Precision of the method and preparation of test samples}

To calculate the percent of RSD and quantifications of the percent assay, a total of six samples were stetted up for the same homogeneous sample solution preparation then injected to the machine in triplicate for the same sample.

\section{Preparation of intermediate precision sample test}

Using the samples prepared for the method precision test, each sample of the six samples is injected in triplicate but at a different time and then analyzed. Percent of RSD and assay were calculated for each one of them (10).

\section{Preparation of linearity test samples}

In order to evaluate the linearity of the samples under test, five standard samples were prepared with concentrations: $50 \%, 80 \%, 100 \%, 120 \%$, and $150 \%$ of the standard sample concentration for Alogliptin, Pioglitazone, and Metformin. Each sample was injected in triplicate for the purpose of analysis, and then linear analysis was performed on the bases of average peak areas versus the concentration of level studied.

\section{Preparation of accuracy test samples}

To evaluate the accuracy of the method used, three samples were prepared by dissolving the following concentrations in the same mobile phase used in the original analysis. The concentrations were $150 \%, 100 \%$, and $50 \%$ in $50 \mathrm{~mL}$ mobile phase. The corresponding standard solutions were prepared in the same way as the previous samples. All of the samples and standards were used in triplicate, i.e., the same concentration was injected in triplicate (10).

\section{Preparation of solutions for stability of analytical solutions study}

We used the (ICH) guideline for evaluation of the Stability of Analytical Solutions. The evaluation was conducted at ambient temperate $\left(25^{\circ} \mathrm{C}\right.$, freshly prepared samples) and $24 \mathrm{~h}$ later. The results were obtained by comparing the two solutions that were prepared at two different times (11).

\section{Preparation of robustness tests}

- Robustness with regarding wavelength (+3 and $-3)$

- Robustness with regarding the changes in $\mathrm{pH}$ $(+0.2$ and -0.2$)$

- Robustness with regarding the changes in temperature (+3 and -3$)$

- Robustness with regarding the changes in organic modified composition ( $+5 \%$ and $-5 \%)$

Changes were made to evaluate their effects on the method. Obtained data for each factor was evaluated by calculating \%RSD and percent of the recovery.

\section{Preparation of selectivity test solutions}

In this test, we used both the local drug and foreign one, where both of them were dissolved separately in the same mobile phase. On the other hand, the sample solution was prepared by utilizing the raw material for the preparation of the corresponding test solution in the same mobile phase in addition to the placebo, which was injected into the machine and regarded as reference formulation.

\section{Preparation of force degradation test samples}

To enforce degradation in the samples, we used the following challenging acid, and bases were added to the raw material like the following: $5 \mathrm{~mL}$ of $1 \mathrm{M}$ $\mathrm{HCl}$ added to the raw material for one hour. Consequently, the raw material was treated with $5 \mathrm{~mL}$ of each of $1 \mathrm{~N} \mathrm{HCl}, 1 \mathrm{~N} \mathrm{NaOH}, 1 \mathrm{~N} \mathrm{H}_{2} \mathrm{O}_{2}$, and purified water, separately for $30 \mathrm{~min}$, and then the mobile phase was used as a solvent to dissolve each of the formerly mentioned solutions. On the other hand, the standard solution was prepared. Then, all of the previous solutions were injected into the machine.

\section{Recovery (Accuracy)}

A triplicate of solutions containing each of Alogliptin, Pioglitazone, and Metformin was pre- 
pared. Then, each one of the solutions is injected, and the total peak areas of former solutions were compared to one obtained from equivalent mobile phase standards that are containing specific dilution of analytes confirming to obtain $100 \%$ recovery, and the same treatment for the IS. Recovery has conducted a series of solutions containing Alogliptin, Pioglitazone, and Metformin, each one with QC level in the mobile phase.

\section{RESULTS AND DISCUSSION}

\section{Method development and optimization}

In order to develop a suitable method for analysis of the three drugs together using HPLC, we tried several combinations, as shown in Table 1, where we were tried by keeping changing of different buffers, $\mathrm{pH}$, mobile phase composition, flow rate, column, and absorbance. However, all of the trial methods result in several overlaps, asymmetrical peaks, and irregular chromatograms either for the drugs alone or the mixture in solutions. One method was exceptional in that it gives the inverse of the formerly mentioned properties, with a com- position of $70: 30$ (acetonitrile: buffer), and has a $\mathrm{pH}$ of 3.4. This method was the best in the symmetry of peaks, retention time, and resolution. The results are shown in Table 1.

\section{Method validation \\ Precision \\ System precision}

The motivation behind the "system precision" test is to discover the level of coinciding between singular test outcome when the technique is applied over and over to various injections (i.e., ten injections) of the identical homogeneous sample (12). The percent of RSD values were underneath $2 \%$, demonstrating excellent system suitability. Furthermore, the initial and the final retention times of each one do not overlap, indicating proper resolution, as shown in Table 2.

The chromatogram shows a good separation of Alogliptin, Pioglitazone, and Metformin with no overlapping between the peaks acquired from resolution data, which suggests a precise system, as shown in Figure 2.

Table 1. Results of the method optimization.

\begin{tabular}{|l|c|c|c|}
\hline \multicolumn{1}{|c|}{ Trial no. } & Trial 1 & Trial 2 & Trial 3 \\
\hline Column & $\begin{array}{c}\text { Column: ACE C8 }- \\
(250 \mathrm{~mm} \times 4.6 \mathrm{~mm}), 5 \mu \mathrm{m}\end{array}$ & $\begin{array}{c}\text { Column: ACE C18 - } \\
(150 \mathrm{~mm} \times 4.6 \mathrm{~mm}), 5 \mu \mathrm{m}\end{array}$ & $\begin{array}{c}\text { Column: ACE C18 - } \\
(250 \mathrm{~mm} \times 4.6 \mathrm{~mm}), 5 \mu \mathrm{m}\end{array}$ \\
\hline Mobile phase & $\begin{array}{c}50: 50(\text { Buffer: acetonitrile }) \\
\text { adjusted to } \mathrm{pH} 3.4\end{array}$ & $\begin{array}{c}30: 70(\text { Buffer: acetonitrile }) \\
\text { adjusted to } \mathrm{pH} 3.4\end{array}$ & $\begin{array}{c}30: 70(\text { Buffer: acetonitrile }) \\
\text { adjusted to } \mathrm{pH} 3.4\end{array}$ \\
\hline Detection & wavelength: $254 \mathrm{~nm}$ & wavelength: $230 \mathrm{~nm}$ & wavelength: $230 \mathrm{~nm}$ \\
\hline Injection volume & $20 \mu \mathrm{L}$ & $10 \mu \mathrm{LL}$ & $1.0 \mathrm{~mL}$ per min \\
\hline Flow rate & $0.5 \mathrm{~mL}$ per min & $25^{\circ} \mathrm{C}$ & $25^{\circ} \mathrm{C}$ \\
\hline Oven temperature & $25^{\circ} \mathrm{C}$ & Poor resolution & Good resolution \\
\hline Observation & Poor resolution & Rejected method & Accepted method \\
\hline Result & Rejected method & & \\
\hline
\end{tabular}

Table 2. System parameters for simultaneous of measurement diluent-containing Alogliptin, Pioglitazone and Metformin.

\begin{tabular}{|l|c|c|c|}
\hline \multicolumn{1}{|c|}{ Parameters } & Alogliptin & Pioglitazone & Metformin \\
\hline Average area of 10 injections & 662007.5 & 1222902.8 & 2705026.6 \\
\hline RSD\% & 0.041 & 0.031 & 0.047 \\
\hline Asymmetry & 1.02 & 1.3 & 0.97 \\
\hline Theoretical plates & 8457 & 8457 & 8457 \\
\hline Resolution & 6.3 & 1.6 & 6.3 \\
\hline Initial retention time & 3.1 & 3.4 & 1.8 \\
\hline Final retention time & 3.3 & 3.6 & 2.2 \\
\hline
\end{tabular}


Table 3. Precision of the analytical method for a sample containing Alogliptin.

\begin{tabular}{|c|c|c|c|c|c|c|c|c|}
\hline $\begin{array}{c}\text { Sample } \\
\text { no. }\end{array}$ & $\begin{array}{c}\text { Weight } \\
\mathrm{g}\end{array}$ & $\begin{array}{c}\text { Metformin } \\
\text { area }\end{array}$ & $\begin{array}{c}\text { IS } \\
\text { area }\end{array}$ & $\begin{array}{l}\text { Area } \\
\text { ratio }\end{array}$ & $\begin{array}{l}\text { Conc. } \\
\mathrm{mg} / 100\end{array}$ & Accuracy & A.V & $\begin{array}{c}\mathrm{RSD} \\
\%\end{array}$ \\
\hline 1 & 41.7 & 664004 & 3953485 & 0.16795 & 42.251 & 101.322 & \multirow{6}{*}{99.8} & \multirow{6}{*}{1.32} \\
\hline 2 & 41.02 & 662026 & 4036014 & 0.16403 & 41.218 & 100.483 & & \\
\hline 3 & 41.23 & 650057 & 3978575 & 0.16339 & 41.050 & 99.563 & & \\
\hline 4 & 42.02 & 653399 & 3986016 & 0.16392 & 41.190 & 98.025 & & \\
\hline 5 & 41.8 & 671600 & 4101597 & 0.16374 & 41.142 & 98.427 & & \\
\hline 6 & 40.8 & 659197 & 4030220 & 0.16356 & 41.096 & 100.725 & & \\
\hline
\end{tabular}

Table 4. Precision of the analytical method for a sample containing Pioglitazone.

\begin{tabular}{|c|c|c|c|c|c|c|c|c|}
\hline $\begin{array}{c}\text { Sample } \\
\text { no. }\end{array}$ & $\begin{array}{c}\text { Weight } \\
\mathrm{g}\end{array}$ & $\begin{array}{l}\text { Metformin } \\
\text { area }\end{array}$ & $\begin{array}{c}\text { IS } \\
\text { area }\end{array}$ & $\begin{array}{l}\text { Area } \\
\text { ratio }\end{array}$ & $\begin{array}{c}\text { Conc. } \\
\mathrm{mg} / 100\end{array}$ & Accuracy & A.V & $\begin{array}{c}\text { RSD } \\
\%\end{array}$ \\
\hline 1 & 48.2 & 1193988 & 3953485 & 0.30201 & 48.002 & 99.588 & \multirow{6}{*}{100.0} & \multirow{6}{*}{1.13} \\
\hline 2 & 48.2 & 1216522 & 4036014 & 0.30142 & 47.901 & 99.380 & & \\
\hline 3 & 47.3 & 1193297 & 3978575 & 0.29993 & 47.649 & 100.738 & & \\
\hline 4 & 47.5 & 1194485 & 3986016 & 0.29967 & 47.605 & 100.221 & & \\
\hline 5 & 47.2 & 1237140 & 4101597 & 0.30162 & 47.936 & 101.560 & & \\
\hline 6 & 48.2 & 1202730 & 4030220 & 0.29843 & 47.395 & 98.329 & & \\
\hline
\end{tabular}

Table 5. Precision of the analytical method for a sample containing metformin.

\begin{tabular}{|c|c|c|c|c|c|c|c|c|}
\hline $\begin{array}{c}\text { Sample } \\
\text { no. }\end{array}$ & $\begin{array}{c}\text { Weight } \\
\text { g }\end{array}$ & $\begin{array}{l}\text { Alogliptin } \\
\text { area }\end{array}$ & $\begin{array}{c}\text { IS } \\
\text { area }\end{array}$ & $\begin{array}{l}\text { Area } \\
\text { ratio }\end{array}$ & $\begin{array}{l}\text { Conc. } \\
\mathrm{mg} / 100\end{array}$ & Accuracy & A.V & $\begin{array}{c}\mathrm{RSD} \\
\%\end{array}$ \\
\hline 1 & 39.47 & 2682731 & 3953485 & 0.67857 & 39.035 & 98.898 & \multirow{6}{*}{99.2} & \multirow{6}{*}{0.94} \\
\hline 2 & 37.7 & 2659947 & 4036014 & 0.65905 & 37.838 & 100.365 & & \\
\hline 3 & 38.7 & 2631652 & 3978575 & 0.66146 & 37.985 & 98.153 & & \\
\hline 4 & 36.21 & 2525555 & 3986016 & 0.63360 & 36.276 & 100.183 & & \\
\hline 5 & 37.14 & 2632394 & 4101597 & 0.64180 & 36.779 & 99.028 & & \\
\hline 6 & 39.14 & 2697334 & 4030220 & 0.66928 & 38.465 & 98.275 & & \\
\hline
\end{tabular}

\section{Method precision}

To evaluate the precision of the method, we conducted an analysis and repeated it six times for the mixture of the three drugs. The percent of RSD values were underneath $2 \%$, demonstrating that the method has precision for the samples in the used diluent. Also, the recovered concentrations were found to be in the range of $98-102 \%$ for either sample (Tables 3-5).

The data presented in Tables 4-6 show that the mean value of assay $\%$ fall between (98-102\%) and the RSD is under $2 \%$, according to ICH guidelines, both of them fall inside the accepted range. As a result, the presented method was found to be precise.
Moreover, the chromatograms show a good separation of Alogliptin, Pioglitazone, Metformin, and IS with no overlapping between the peaks, which indicate that the used method is precise.

\section{Intermediate precision}

Intermediate precision is achieved by doing the test on two different days and using different equipment. In both different days and using the same conditions of the assay, six samples were analyzed, obtaining percent assay and RSD for both days. The result that we obtained is assayed value fall between $99-102 \%$.

The results achieved were in the acceptable limit, which is assay and RSD percent, which implies that the method is valid. The result of the 
intermediate precision chromatogram is illustrated in Figure 3.

Fortunately, results show a good separation of the three drugs (Alogliptin, Pioglitazone, and Metformin) from each other, as illustrated in Figure 2, with limited overlapping between the peaks, which imply a good intermediate precision.

\section{Linearity and range}

A progression of standard samples at various concentrations of the objective compounds was set up to assess the linearity. Once the samples are analyzed two times, a plot of linear regression analysis was sketched based on the average peak areas versus the concentration of the levels investigated. The correla- tion coefficient was 0.9998, which indicates good linearity for Alogliptin, which falls inside the stated limit to investigate the linearity validation method. Pioglitazone and metformin were investigated in the same interval. A good linear relationship $\left(r^{2}=0.9998\right)$ was noticed between the concentrations and the corresponding average area. The calibration curve equation $=0.0059 \mathrm{x}+0.0188$. The calibration curve of Pioglitazone was linear over the concentration limit of (20-250 ppm). A good linear relationship $\left(\mathrm{r}^{2}=\right.$ 0.9998) was observed between the concentrations and the corresponding average area. The calibration curve equation: Absorbance $=0.0163 x+0.0423$. The calibration curve of Pioglitazone was linear over the concentration range of (20-250 ppm).



Figure 2. The resolution pattern of Alogliptin, Pioglitazone, and Metformin mixture.

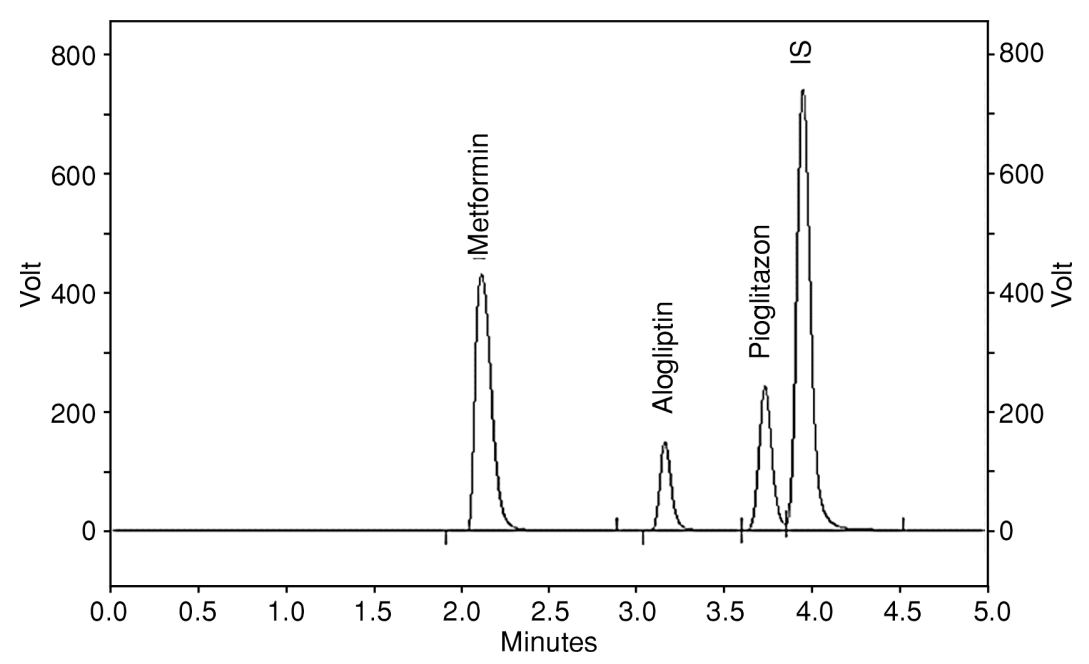

Figure 3. Chromatogram of intermediate precision. 

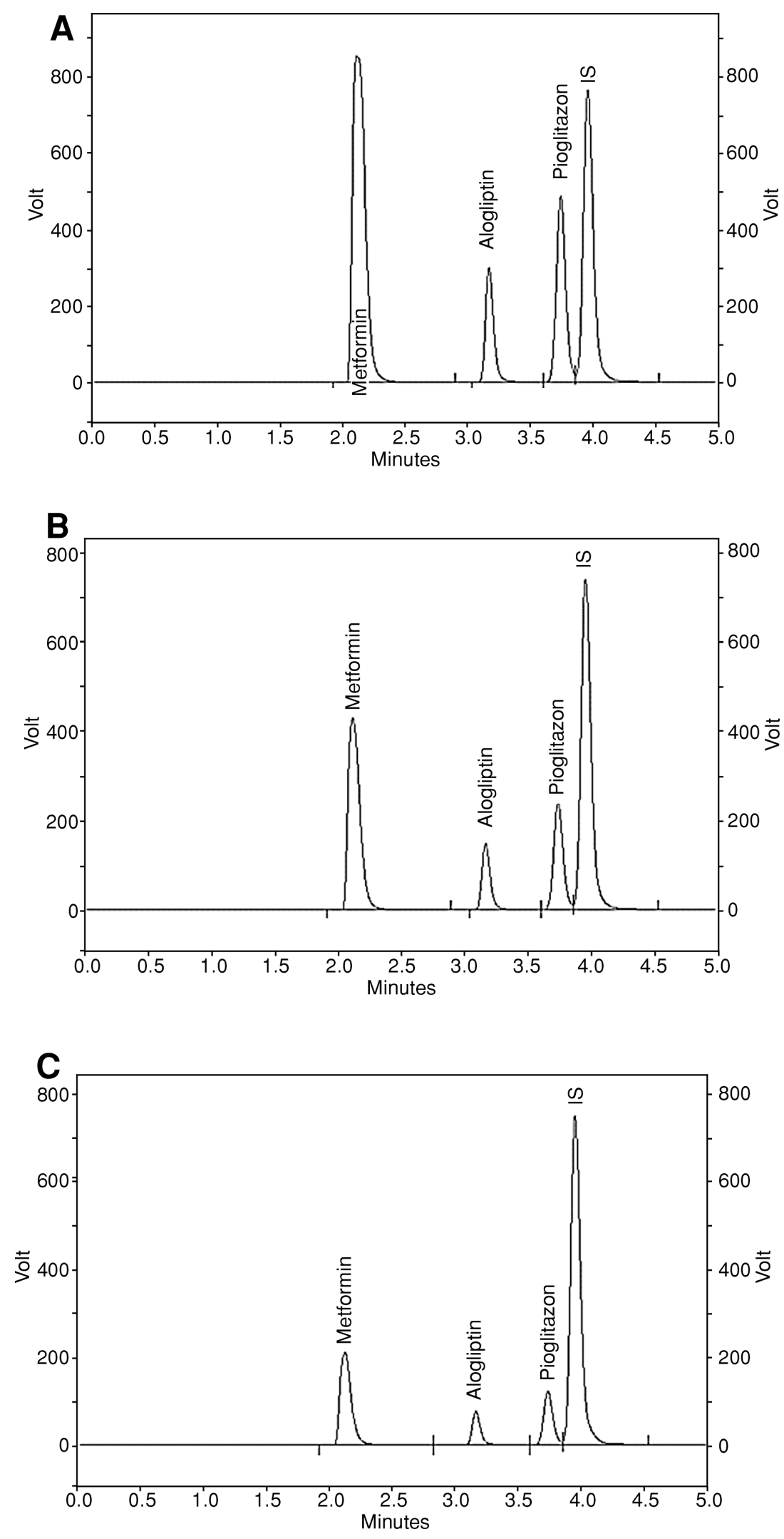

Figure 4. Accuracy results level A) 50\%, B) $100 \%$, C) $150 \%$. 


\section{Recovery "Accuracy"}

For the purpose of evaluating the accuracy of the method, we analyzed samples at 50\%, 100\%, and
$150 \%$ concentration. At each percent value, the injection was repeated three times in comparison to the standard sample. These results are illustrated in Tables 4-6.
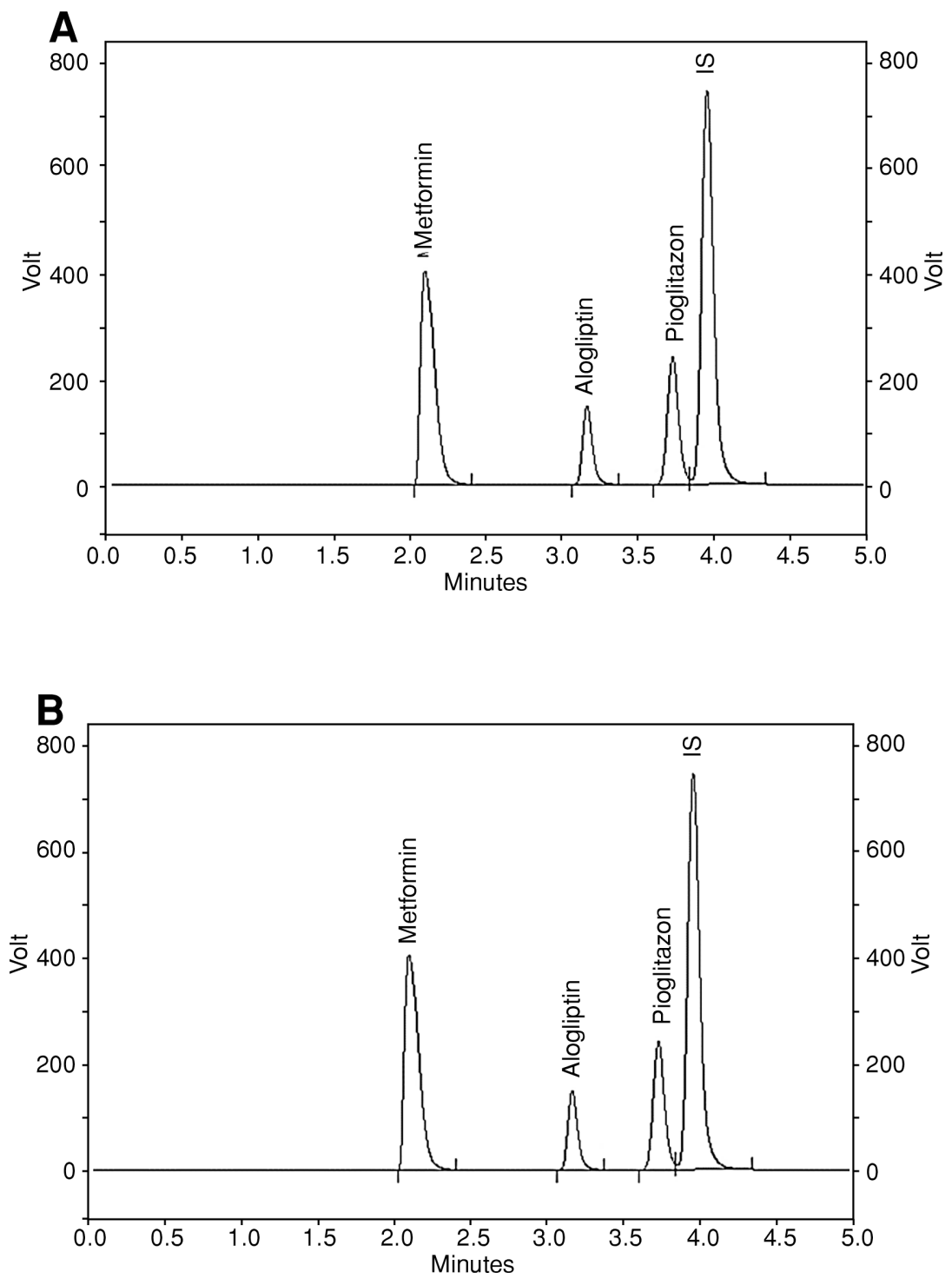

Figure 5. Chromatogram of Alogliptin, Pioglitazone, and Metformin: A) using $227 \mathrm{~nm}$ wavelength, B) using $233 \mathrm{~nm}$ wavelengt.

Table 6. Stability for Alogliptin, Pioglitazone, and in the diluent solution.

\begin{tabular}{|c|c|c|}
\hline Drug & Time and temperature & Assay \% \\
\hline \multirow{3}{*}{ Alogliptin } & Standard fresh sample & 100.23 \\
\cline { 2 - 3 } & $24 \mathrm{~h}$ at $25^{\circ} \mathrm{C}$ & 99.81 \\
\hline \multirow{2}{*}{ Pioglitazone } & Standard fresh sample & 98.87 \\
\cline { 2 - 3 } & $24 \mathrm{~h}$ at $25^{\circ} \mathrm{C}$ & 98.01 \\
\hline \multirow{2}{*}{ Metformin } & Standard fresh sample & 98.73 \\
\cline { 2 - 3 } & $24 \mathrm{~h}$ at $25^{\circ} \mathrm{C}$ & 98.60 \\
\hline
\end{tabular}



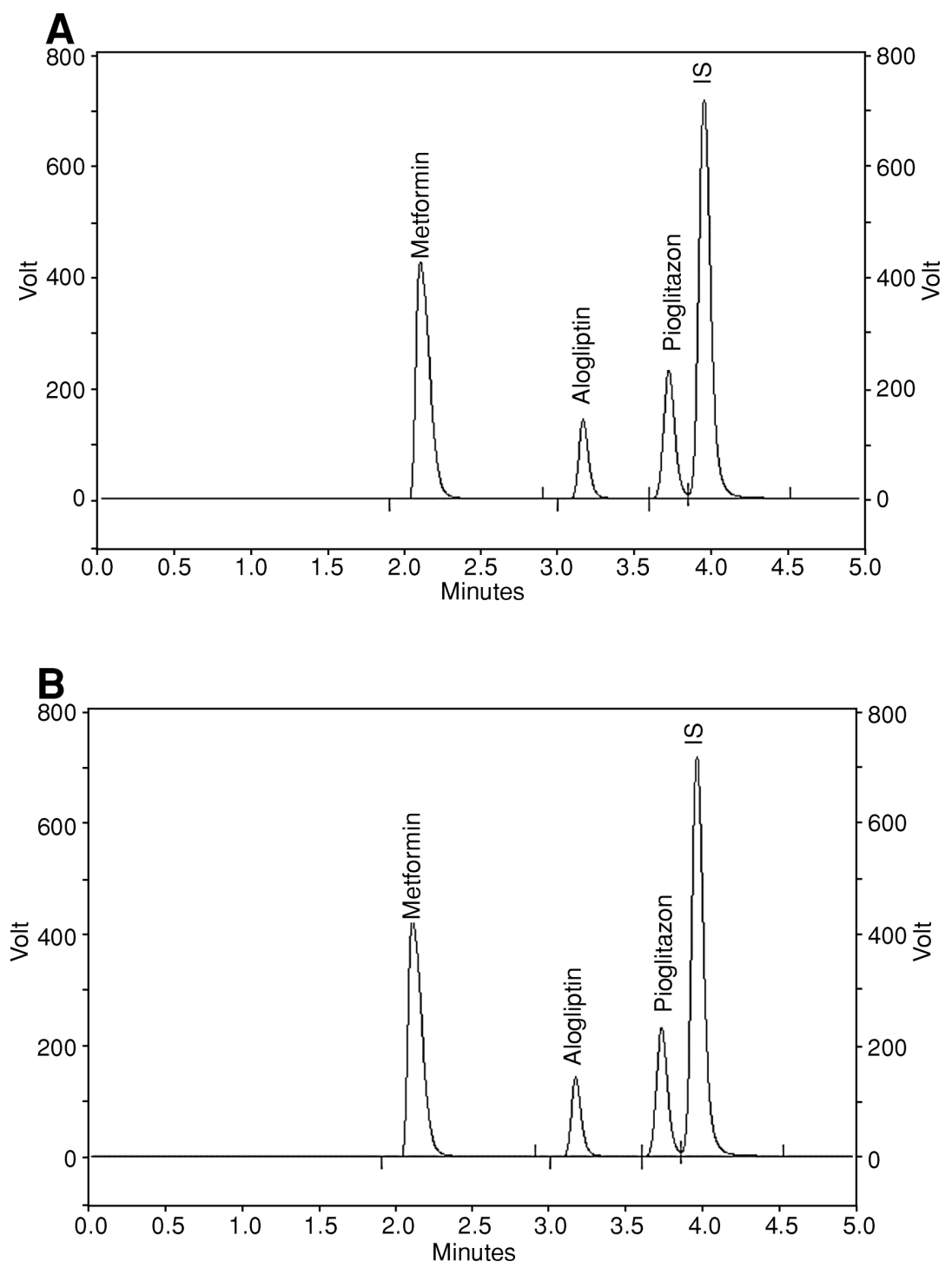

Figure 6. Chromatogram of Alogliptin, Pioglitazone and Metformin: A) at pH 3.2 B) pH 3.6 of the mobile phase, respectively.

The $\%$ of recovery equation:

$\%$ Accuracy $=\frac{\text { recovered amount }}{\text { actual amount }} \times 100$, The accepted limits of recovery are $98-102 \%$ according to ICH guidelines.

Concentrations levels are 31,62 , and $125 \mathrm{ppm}$ for Alogliptin, 19.47, 9.32, and $4.45 \mathrm{ppm}$ for Pioglitazone, and 6801.04, 3112.71, and 1388.84 ppm were analyzed and calculated from a standard curve. The profiles of the three different concentrations revealed a direct relationship between the peak height and concentration (Figure 4).

The three tables are implying a good recovery value; all data observed are according to ICH.

In addition to the excellent separation seen from the peaks, Figure 4 shows the link in which the variation in concentration ranges will result in a change in the area of peak (AUC), by elevating the concentration, the AUC will increase.

As can be seen from the previous results, Alogliptin, Pioglitazone, and Metformin show a valid test accuracy result.

Stability of drugs in the analytical solution One of the essential things that should be considered during the analysis is the stability of our drug and in which range (13). Usually, the stability is evaluated by storing a particular concentration of the solution under test for $24 \mathrm{~h}$ in the ambient temperature, and then comparing it with a new standard solution (14). $100 \%$ concentration level is analyzed against the standard solution; for each sample, the concentra- 
tion is $62 \mathrm{ppm}$ of Alogliptin, $9.32 \mathrm{ppm}$ of Pioglitazone, and $3112.71 \mathrm{ppm}$ of Metformin. The stability results fall in the stated limit range of 98$102 \%$ for fresh samples and in $24 \mathrm{~h}$, are listed in Table 6.

Results show that the assay percentage under all tested conditions comply with ICH guideline. As a result, we can conclude that Alogliptin. Pioglitazone and metformin are stable throughout the test conditions.

\section{Robustness}

Robustness can be achieved by modifying the procedure parameters within a certain limit, and the results should not change dramatically. Robustness depends on the procedure applied.

Robustness was evaluated by utilizing solutions prepared in the same way that the system or methods was prepared, with replicates equal to three, and was assessed concerning system suitability parameters or on recovered amounts. Both of them were compared to the results obtained by the original method. Changes were performed separately as in the following: detector wavelength $( \pm 3 \mathrm{~nm})$; the $\mathrm{pH}$ of the mobile phase $( \pm 0.2)$ unit of the specified value to show if there is any effect of changes in $\mathrm{pH}$ value; mobile phase composition $( \pm 5-10 \%)$ acetonitrile volume; temperature $\pm 3^{\circ} \mathrm{C}$.
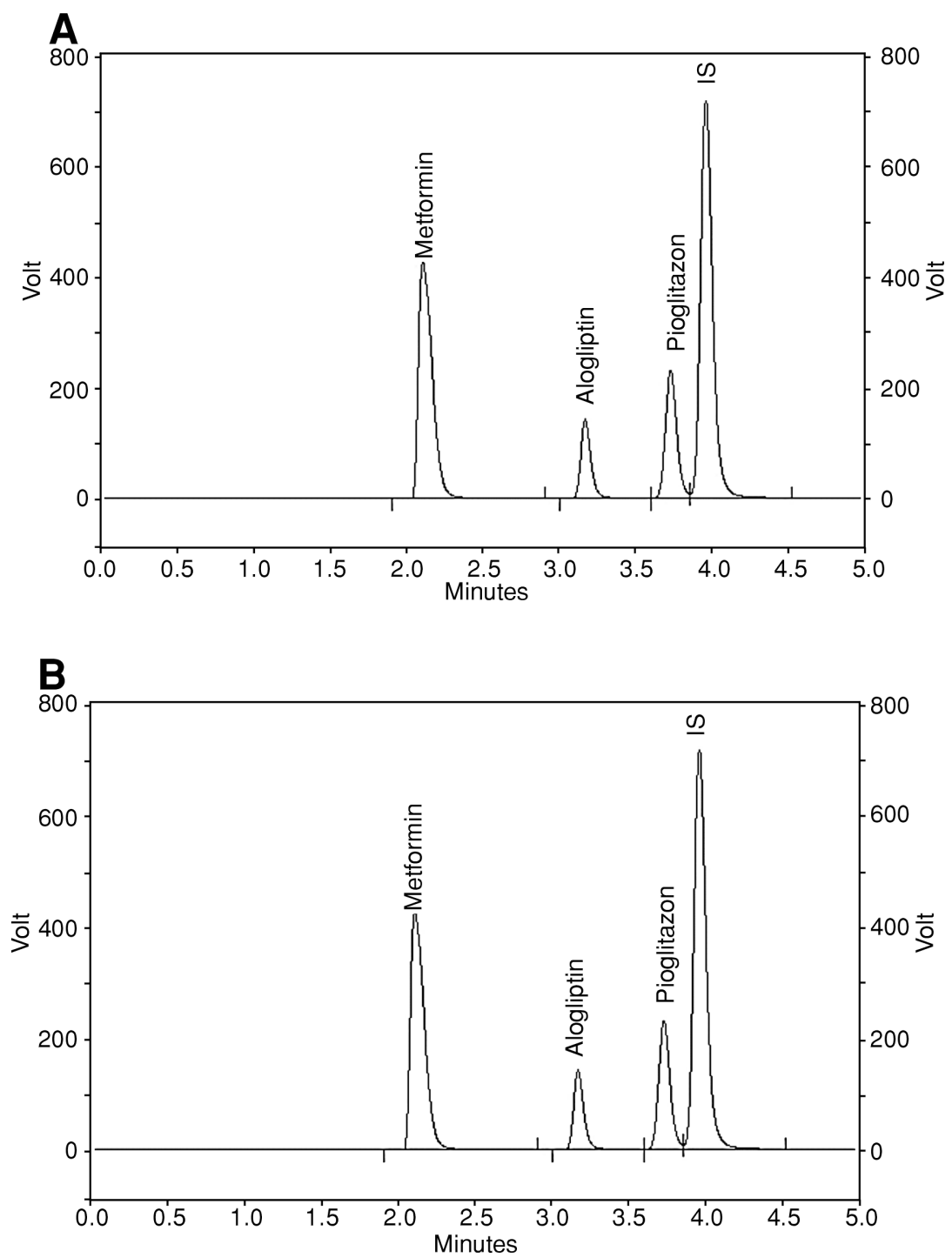

Figure 7. Chromatogram of Alogliptin, Pioglitazone, and Metformin when setting the temperature at A) $\left.28^{\circ} \mathrm{C}, \mathrm{B}\right) 22^{\circ} \mathrm{C}$. 

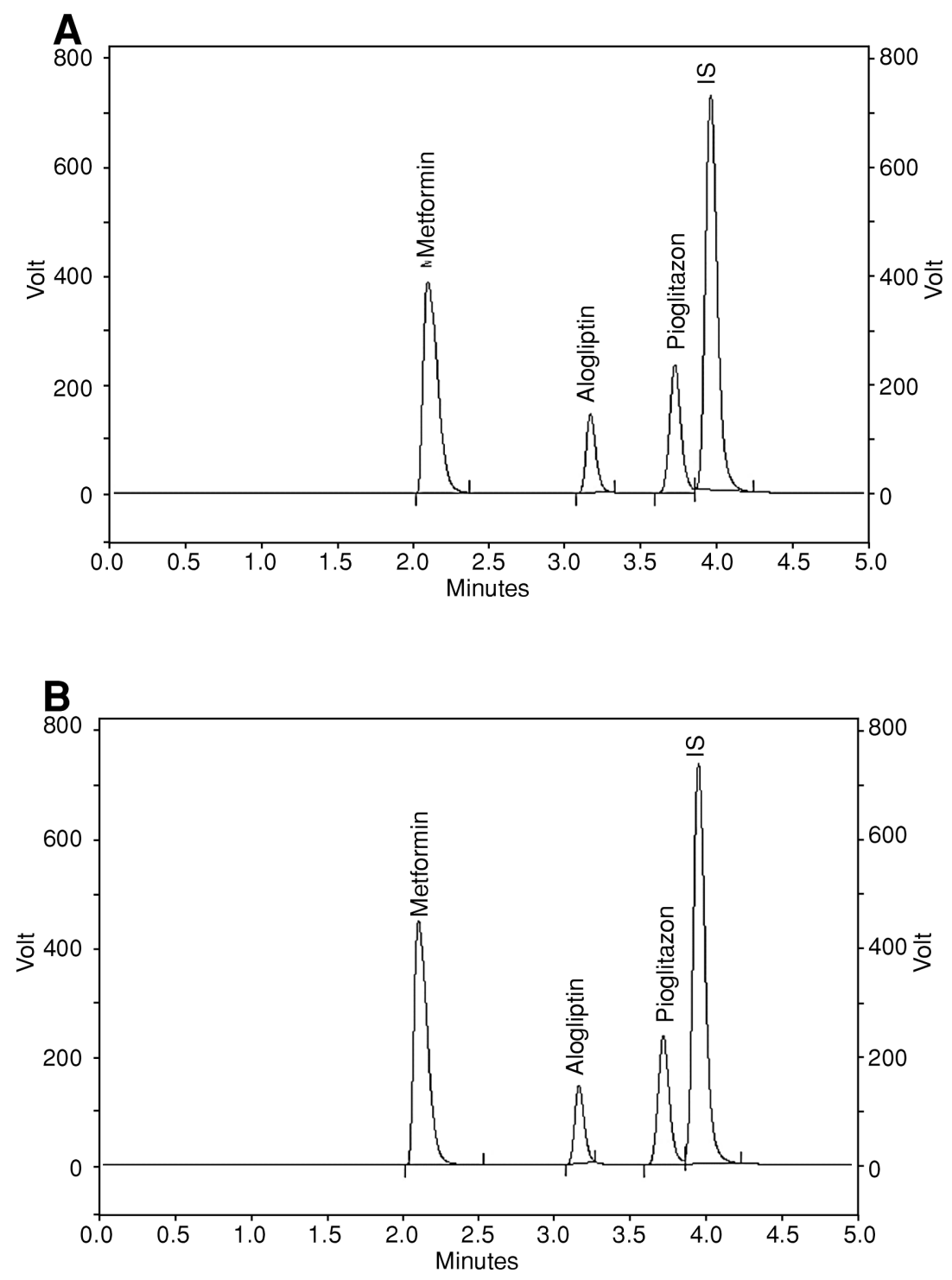

Figure 8. Chromatogram of Alogliptin, Pioglitazone, and Metformin assayed in A) 5\% increase of ACN B) 5\% decrease of CAN.

\section{Robustness regarding wavelength}

To study the capacity of the method to withstand small changes, a small change $( \pm 3)$ in wavelength has been done in the analytical method. One analytical concentration was analyzed at each level against a standard solution. The RSD $\%$ was $<2 \%$ revealing that a slight variation in wavelength will not affect the detection parameters of the assay, Figure 5.

A variation in wavelength $( \pm 3)$ can lead to a slight change in AUCs of Alogliptin, Pioglitazone, and Metformin. However, RSD percent values stay inside the accepted range $(<2 \%)$. This indicates that the present method is robust.

\section{Robustness regarding $\mathbf{p H}$}

Similarly, slight changes in $\mathrm{pH}$ of the diluent were made to evaluate if this change affects the detection parameters of the drugs. The percentage of both the assay and RSD were close to $100 \%$ and $<1 \%$, respectively, revealing that a small variation in $\mathrm{pH}$ does not affect the detection parameters of Alogliptin, Pioglitazone, or Metformin, Figure 6.

From the previous results, we can conclude that there is no or little variation in the peak area with changes in $\mathrm{pH}$. This intern ensures that the analytical method is robust for Alogliptin, Pioglitazone, and Metformin. 





Figure 9. Chromatograms of Alogliptin, Pioglitazone, and Metformin following the addition of A) acid B) base C) $\mathrm{H}_{2} \mathrm{O}_{2}$ D) $\mathrm{H}_{2} \mathrm{O}$ E) 4 hours of sunlight exposure.

\section{Robustness regarding temperature}

Fluctuation in the temperature was another variable that is tested for robustness. This test is conducted by the fluctuation of the temperature of the standard solution at $25^{\circ} \mathrm{C}$ by $\pm 3^{\circ} \mathrm{C}$. The results of this test were the RSD percent fluctuates $<2 \%$, as shown in Figure 7.

The conclusion that can be inferred from the previous results is that the analytical method is robust for Alogliptin, Pioglitazone, and Metformin.

\section{Robustness of the organic modified composition}

To test whether the analytical method can be affected by small changes in the ingredients in the mobile phase, we performed this test (15). At level $100 \%$, analytical concentration is analyzed against a standard solution. The results are listed in Figure 8.

Results inferred from the previous tables show that the method is robust since the RSD percent was lower than $2 \%$.

\section{Forced degradation test}

For identifying degradation products and the mechanism of breakdown, stress testing of the drug substance was conducted (16). The condition under which this breakdown occurs, and appropriate methodology for assessing stability, can also help in establishing the degradation pathway(s). 
Acidic, basic, hydrolysis, and oxidation degradations were used to test the detection parameters of the method. Specific volumes of $1 \mathrm{~N} \mathrm{HCl}, 1 \mathrm{~N}$ $\mathrm{NaOH}, 1 \mathrm{~N}$ Hydrogen Peroxide, and purified water were added separately to the solution of Alogliptin, Pioglitazone, and Metformin for $30 \mathrm{~min}$ after that analysis was done. The inferred results revealed that the RSD percent values were $<1 \%$ Figure 9.

Moreover, exposure of the samples for the usual day sunlight for four hours analyzing them revealed that no additional peaks were found, which indicates that Alogliptin, Pioglitazone, and Metformin are not light sensitive drugs Figure 9-E.

\section{Selectivity}

The developed analytical methods should be ensured its ability to accurately quantify with specificity the presence of the active ingredients, placebo, and all of another ingredient (17). After following the developed method and injection of the standard, sample, solvent, and a placebo solution according to it, we found that there is no interference either between analyte and solvent nor with placebo.

\section{Placebo effect}

The placebo usually is containing all of the ingredients except the active ones. Here in our case, the placebo is consisting of mannitol, microcrystalline cellulose, hydroxypropyl cellulose, croscarmellose sodium, magnesium stearate, purified water, Hypermellose 2910, titanium dioxide, iron oxide red (E172), Macrogol 8000, and butyl alcohol. In order to prepare the placebo solution, water-acetonitrile-methanol was mixed in a ratio $1: 1: 1$ and used as a solvent. After that, the solution was injected into the system for analysis.

\section{Conflict of interest}

The authors declare no conflicts of interest.

\section{REFERENCES}

1. Leslie R.D., Palmer J., Schloot N.C., Lernmark A.: Diabetologia 59, 13 (2016).

2. White W.B., Heller S.R., Cannon C.P., Howitt H., Khunti K., et al.: Am. J. Med. 131, 813 (2018).

3. Alam F., Islam M.A., Mohamed M., Ahmad I., Kamal M.A., et al.: Sci. Rep. 9, 1 (2019).

4. Fortun S., Schmitzer A.R.: ACS Omega 3, 1889 (2018).

5. Bailey C.J.: Diabetologia 60, 1566 (2017).

6. Vocilkova L., Opatrilova R., Sramek V.: Curr. Pharm. Anal. 5, 424 (2009).

7. Wael Abu Dayyih L.T.: Pharm. Anal. Acta 5, 3 (2014).

8. Wankhede S. B., Wadkar S. B., Raka K. C. , Chitlange S. S.: Indian J. Pharm. Sci. 71, 563 (2009).

9. Wael Abu Dayyih T.A., Al Saadi N., Hamad M., Mallah E., Matalka K.: Int. J. Pharm. Sci. Res. 3, 3686 (2013).

10. Patel J.K., Patel N.K.: Sci. Pharm. 82, 749 (2014).

11. ICH: Ich.Org. (2008).

12. Hamad M., Rahhal A., Dayyih W.A., Mallah E., Dayyih A.A., et al.: J. Pharm. Bioall. Sci. 11, 60 (2019).

13. Blessy M., Patel R.D., Prajapati P.N., Agrawal Y.K.: J. Pharm. Anal. 4, 159 (2014).

14. Uney K., Altan F., Elmas M.: Antimicrob. Agents Chemother. 55, 854 (2011).

15. Dayyih W.A., Hamad M., Mallah E., Dayyih A.A., Mansoor K., et al.: Curr. Pharm. Anal. 15, 165 (2017).

16. Jadhav S.B., Reddy P.S., Narayanan K.L., Bhosale P.N.: Sci. Pharm. 85, 25 (2017).

17. Bharti Mittu A.C., Chauhan P.: J. Anal. Bioanal. Tech. 6, 1 (2015). 